\title{
Restructuring Hospital Industry to Control Public Health Care Expenditure: The Role of Input Substitutability
}

Massimiliano PIACENZA, Gilberto TURATI, Davide VANNONI

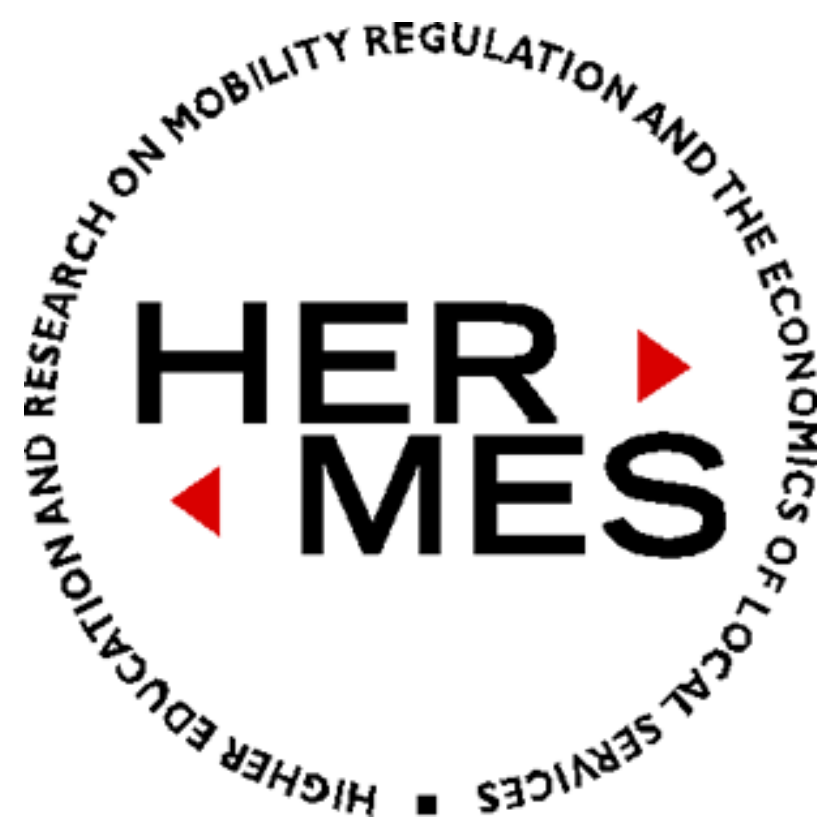




\author{
(c) HERMES \\ Fondazione Collegio Carlo Alberto \\ Via Real Collegio, 30 \\ 10024 - Moncalieri (TO) \\ Tel: 0116705250 \\ Fax: 0116705089 \\ info@hermesricerche.it \\ http:/ / www.hermesricerche.it
}

I diritti di riproduzione, di memorizzazione e di adattamento totale o parziale con qualsiasi mezzo (compresi microfilm e copie fotostatiche) sono riservati.

\title{
PRESIDENTE
}

Giovanni Fraquelli

\section{SEGRETARIO}

Cristina Piai

\section{COMITATO DIRETTIVO}

Giovanni Fraquelli (Presidente)

Cristina Piai (Segretario)

Guido Del Mese (ASSTRA)

Carla Ferrari (Compagnia di San Paolo)

Giancarlo Guiati (GTT S.p.A.)

Mario Rey (Università di Torino)

\section{COMITATO SCIENTIFICO}

Tiziano Treu (Presidente, Università "Cattolica del Sacro Cuore" di Milano e Senato della Repubblica) Giuseppe Caia (Università di Bologna)

Roberto Cavallo Perin (Università di Torino)

Giovanni Corona (CTM S.p.A.)

Graziella Fornengo (Università di Torino)

Giovanni Fraquelli (Università del Piemonte Orientale "A. Avogadro")

Carlo Emanuele Gallo (Università di Torino)

Giovanni Guerra (Politecnico di Torino)

Marc Ivaldi (IDEI, Universitè des Sciences Sociales de Toulouse)

Carla Marchese (Università del Piemonte Orientale "A. Avogadro")

Luigi Prosperetti (Università di Milano "Bicocca")

Alberto Romano (Università di Roma "La Sapienza")

Paolo Tesauro (Università di Napoli "Federico" II) 


\title{
Restructuring Hospital Industry to Control Public Health Care Expenditure: The Role of Input Substitutability
}

\author{
Massimiliano Piacenza \\ (University of Torino, piacenza@econ.unito.it) \\ Gilberto Turati \\ (University of Torino,turati@econ.unito.it) \\ Davide Vannoni \\ (University of Torino,vannoni@econ.unito.it)
}

This version, April $15^{\text {th }}, 2008$

\begin{abstract}
In this paper we investigate the economic rationality of the bed downsizing process, characterising the hospital industry worldwide in the last decades, as a measure to control public health care expenditure. Considering a sample of Italian hospitals, we provide fresh evidence on the factor substitutability in the production of hospital services. Differently from other studies, based on North-American data and confined to pre-determined cost function models, we estimate a general specification (the Generalised Composite), and test it against traditional nested models (e.g., the translog). For all the specifications we derive Allen, Morishima and Shadow elasticities of substitution between input pairs, obtaining a fairly consistent picture across all models and elasticity concepts. In particular, our results highlight a very limited degree of substitutability between factors in the production of hospital services, especially between beds and medical staff. These findings suggest that a restructuring policy of the hospital industry, which is confined to limiting the number of beds without involving workforce management, could not be a viable strategy for controlling public health care expenditure.
\end{abstract}

Keywords: Public health care expenditure, Hospital industry downsizing, Cost function models, Input substitutability

JEL Codes: D24, H51, I18, L32 


\section{Introduction}

Hospital industries worldwide have been interested by a huge process of reorganisation in the last decades. At the macro level, in order to curb the presence of excess capacity, public producers' number of beds has been reduced by Central or Regional governments almost anywhere (e.g. Kroneman and Siegers, 2004; Hensher et al., 1999). At the micro level, a number of M\&As - interesting both private and public hospitals has been observed in several countries, not only as a response to bed reduction, but also to exploit scale and scope economies, and improve effectiveness and quality of care. The process has been originated on two basic premises: on the one hand, the need to contain public health care expenditure imposed governments to find new ways on how to improve the efficiency (and the effectiveness) in the provision of health services. Empirical analyses on the determinants of health expenditure suggest a positive correlation between the share of inpatients expenditure (i.e., the bulk of hospital costs) and total health spending (e.g., Gerdtham and Jönsson, 2000, and Propper, 2001). As expenditure for hospital services represented (and still represent) a significant share of total health expenditure, it is not surprising that hospitals were clearly at the core of policies aimed at controlling expenditure growth. On the other hand, the perception that an ageing population would have different needs (especially chronic illnesses) with respect to past years caused traditional hospitals - which focus typically on acute care not to be tailored to answer these structural changes in the epidemiological context.

This massive ongoing reshaping of the hospital industry raises of course a number of questions, that only in recent years the academic literature has started to ask. A first problem to address is to understand whether M\&As are justified both from an efficiency and an effectiveness point of view. In this perspective, as discussed in Posnett (1999), results are somewhat mixed. As for efficiency, for instance, studying the 
Canadian Province of Ontario, Preyra and Pink (2006) find large scale unexploited gains from consolidation in the hospital sector, while Bilodeau et al. (2002), concentrating on Québec, show the presence of both economies and diseconomies of scale, with some establishments operating at constant returns to scale. As for effectiveness, for example, focusing on U.S. surgical procedures, Birkmeyer et al. (2002) find that mortality rates are lower the higher the volume of patients treated, whereas Grilli et al. (1998) challenge this view, by surveying literature on cancer patients.

A second question to focus on is the strategic reply of hospitals to bed reductions implemented by Central and Local governments. As for the occupancy rates, Kroneman and Siegers (2004) find for instance that behavioural responses are related to the hospital financing system: in particular, in global budget systems, occupancy rates appear to decline after a reduction in hospital bed supply, while in per diem financing systems, admission rates did not drop following bed downsizing. In both systems, no effects are detected on average length of stay. As for the health expenditure growth, in order to understand the potential role of industry restructuring, an important issue to be discussed concerns workforce management after bed reductions. According to the available literature, there exists a limited substitutability between beds and medical staff. This suggests that, after bed reductions, keeping constant the severity of patients and the quality of treatments, one should observe also a decrease in hospital staffing in order to avoid waste of resources. But while in the U.S. bed downsizing has been accompanied (at least in some cases) with staff reduction, in other countries (especially in Europe) the restructuring of the industry has been limited mostly to beds. This casts some doubts on the effectiveness of this policy in controlling health expenditure growth. 
Since the few papers on the estimation of substitution elasticities in the production of hospital services are limited to non-European data, in this paper we provide first evidence on the degree of substitutability for a representative sample of Italian public hospitals, which properly reflects both the prevalence of public producers of health care services in most European countries, and - most importantly - the prevalence of public funding for health care expenditure. In particular, we estimate different cost function models and derive factors elasticity of substitution, considering all hospitals active in an Italian region ${ }^{1}$. Like other European countries, Italian hospital industry experienced a wide restructuring process; however, downsizing imposed by the Central government has been limited mostly to beds, while workforce reduction has been tackled at the regional level only blocking turnover, causing a large increase in medical staff per bed. Besides uncovering possible inefficiencies which can limit the potentially positive impact of hospital restructuring on health expenditure rationalization, the estimation of input elasticities of substitution is important per se, since the very few studies that have addressed so far this issue did not test the a priori imposed specification for the hospital cost function.

The remainder of the paper is structured as follows: Section 2 surveys economic literature on bed downsizing and its implication for workforce management, including also a discussion of the available estimates of input substitutability in the production of hospital services. Our empirical analysis is presented in Section 3, where we first describe the sample, the explanatory variables used in the cost model, the functional

\footnotetext{
${ }^{1}$ The 20 regions in Italy are the administrative entities in charge of managing health care services at the local level. See France et al. (2005). Notice that, as each region is held responsible of controlling its own health expenditure, this is the appropriate level of analysis for the problem at hand.
} 
forms and the estimation procedures, and then we discuss the results. Section 4 concludes with some implications for the health policy.

\section{Bed downsizing and workforce management}

In this section, we briefly review the scant available literature on the impact of bed downsizing on the staffing of hospitals. The evidence suggests somewhat different effects, according to the prevalence of public or private producers. In the U.S., where the share of private producers is higher than elsewhere, bed downsizing has been sometimes accompanied also with staff reductions, with no clear effects on hospital performance. Chadwick et al. (2004) find for example that Human Resource Management practices are important determinants of successful downsizing, of both beds and the workforce. In particular, looking at financial performance of hospitals, they find a positive impact of consideration for employees' morale and welfare during downsizing (like more extensive communication and advance notice, respectful treatment of laid off employees, attention to survivors' concerns on job security). Somewhat contrary to this view, Aiken et al. (2002a, 2002b) find that better staffing is positively associated with higher nurse-assessed quality of care, lower risk-adjusted and failure-to-rescue rates, lower level of dissatisfaction and burnout, hence suggesting a deterioration of performance following downsizing.

In other countries, especially in Europe, where the share of public producers is higher, the restructuring of the industry has been mainly driven by the need to control public health expenditure growth. Indeed, as shown by an abundant empirical literature (surveyed by, e.g.,Gerdtham and Jönsson, 2000, and Propper, 2001), the ratio of hospital expenditure to total spending is positively related to health care expenditure. However, differently from the U.S., the restructuring process has been limited in most cases to bed downsizing, while workforce management and planning has been 
conducted using fixed ratio relationships (e.g. physicians to patients) that have no empirical validity (e.g. Bloor and Maynard, 2003). Of course, this one-factor restructuring process has caused a consistent change in the input-mix, in particular an increase in medical staff per bed. Several factors can help explain observed variations in input-mix. For instance, a higher need of labour can be related to a higher severity of illness in acute care patients. This might be linked to the increase in patients turnover and the reduction in average length of stay (endogenously determined by clinicians), which characterised hospital industries in countries that adopted a Prospective Payment System. Or it might be a signal of the increase in the quality of services, both perceived by nurses or measured in terms of mortality rates (e.g. Aiken et al., 2002a, 2002b).

In this paper, we aim at understanding whether the observed change in input-mix is economically rational for controlling health expenditure, by focusing on the production technology of hospital services ${ }^{2}$. While estimation of production and cost functions and efficiency analysis have received considerable attention in the literature on the hospital industry, economic studies working out also input substitutability in the production of hospital services are quite rare, and - most importantly - are all based on North-American data. A pioneering study is that by Bothwell and Cooley (1982), focusing on Health Maintenance Organizations in the U.S.. They distinguish four inputs (administrative services, hospital services, medical professional staff services, and capital expenses for maintaining a health centre), and find that administrative services are complements to all the other inputs, but that there is substitution between all other input pairs. In particular, Allen elasticity of substitution between medical staff and

\footnotetext{
${ }^{2}$ As emphasised by Propper (2001), most governments are concerned with health expenditure growth, but the key issue for the appropriate design of health care system is efficiency. Our investigation of the optimal input-mix in the production of hospital services moves along these lines.
} 
capital expenses (the input pair we are most interested in, to understand the observed change in input-mix), is estimated to be 0.638 , which suggest small substitution possibilities. Jensen and Morrisey (1986), studying the U.S. short-term general acute care hospitals, confirm this result, estimating that elasticity of substitution of medical staff with beds ranges between 0.247 (for non-teaching hospitals) to 0.303 (for teaching ones), and elasticity of substitution between nurses and beds ranges between 0.189 and 0.305 (respectively, for the same type of hospitals). These estimates are even lower adjusting output for case-mix. The same difficulties in substituting between inputs is found also for medical staff and nurses, with estimated elasticities close to 0.35 for both types of hospitals. This last result is in contrast with Cowing and Holtmann (1983). Considering New York State hospitals and computing Allen elasticities, they find substantial substitutability between nurses and other types of workers in the short-run, but no estimates are provided for substitution between labour and capital. A more recent study (Bilodeau et al., 2002) considers hospitals in Québec, and estimates an hospital cost function with five inputs (labour, drugs, food, supplies, and energy). While not reporting punctual estimates of Allen elasticities, the authors interpret substitutability of supplies and energy with labour as the hospitals' general ability to substitute capital for labour.

Taken together, the available evidence emphasizes two main points: first, at least in Europe, bed downsizing has not been accompanied also by a reduction in the workforce; second, estimates on factor substitutability in the production of hospital services generally suggest that substitution between capital and medical staff (both physicians and nurses) is rather limited. However, these estimates are mostly based on U.S. data, where the health care services are predominantly produced by private firms and financed with private funds. Thus, it is important - in order to understand the 
effectiveness of bed downsizing on health expenditure - to verify whether this holds true also in the European context. To this end, in the next sections, we provide original evidence on input substitutability, by considering different functional forms and different concepts of elasticity.

\section{Empirical analysis}

\subsection{The sample}

As discussed in the previous sections, the aim of the paper is the study of the technological characteristics of hospital services supply, and the exploration of substitution possibilities among the different inputs involved in the productive process, especially between the number of beds and medical staff (both physicians and nurses). The data used in the econometric analysis have been obtained by the Regione Piemonte (a highly industrialised area in the North-Western part of Italy, which constitutes one of the 20 administrative entities in charge of managing Regional Health Care Systems), and are relative to the productive activity and the cost structure of all the hospitals operating in the 27 Local Health Units (LHU) active during the period 2000-2004. LHU are vertically integrated organisations funded by the Region, and responsible of a whole array of hospital and community services ${ }^{3}$. The sample includes two types of hospitals: those directly managed by the LHU (ASL from now on), and other major hospitals that have been hived off from the LHU and transformed into independent enterprises called Aziende Ospedaliere (AO from now on).

This unique dataset includes all the publicly owned firms involved in the provision of hospital services in Piedmont. The time span covered by the data follows

\footnotetext{
${ }^{3}$ See e.g. France et al. (2005) for a description of the Italian NHS. We stress again that the regional dimension of our dataset represents the correct choice given the regional level of the current organisation of the Italian NHS.
} 
the (still unfinished) reform process of the National Health Service (NHS), so that our units are affected by the downsizing policy of the industry, which has been pursued during the 90 s, and which is still regarded as one of the primary areas of intervention to control the growth in public health expenditure. Planning at the regional level of health care provisions (as envisaged in the recent Piedmont Socio-Health Plan for the years 2006-2010) foresees a reorganisation of the regional hospital network, with the aim of increasing the quality and the effectiveness of services. This would imply a reduction of the required number of beds, due to the planned reduction of average length of stay, and a parallel increase in outpatient treatments, home care services, consultancy and day hospital treatments.

Information on the number of beds and on the quantity and complexity of the services provided (total number of patients, average DRG weight, number of inpatient and outpatient days) have been collected for each single hospital within a LHU and for each AO. The total number of beds, both for inpatient and outpatient treatments, are then computed for each ASL by aggregating the values of the different hospitals which belong to the same LHU. Unfortunately, disaggregated information on the costs and on the labour force are available only for AO, but are not available for each hospital within each LHU. This limitation can represent a problem for ASL units, since staff costs can be related also to community services, rather than hospital services. For such units, considering all costs as relative to the core hospital activity would be inappropriate, so that caution must be put in choosing which type of costs can be included in the study. To that purpose, the different types of costs have been selected and reorganised so as to obtain a measure of operating cost with a composition that can be comparable for ASL and AO structures. We then selected the costs items that are more closely related to the core activity of hospitals, that is the provision of health care services. We come out with 
a final aggregation named operating hospital costs $(\mathrm{OHC}$, the dependent variable in our econometric model) which is the sum of the costs of the following inputs, which are essential for the production of hospital services: labour (both administrative and medical staff), drugs, capital (the measure of which is proxied by the total number of beds). As shown in table 1, for what concerns the relative weight of the different cost categories, the two types of hospitals are very similar. Labour costs are about $86 \%$ of operating hospital costs, while the weights of drugs and depreciation are respectively $9.6 \%$ and $4.4 \%$. OHC has an average value of 79 million euro for ASLs (average yearly growth rate of 3.6\%) and 122 million euro for AOs (average yearly grow rate of $4.8 \%$ ).

[TABLE 1 HERE]

\subsection{Explanatory variables of the cost model}

Exploiting the informative content of the database, we have obtained the following explanatory variables to be included in the estimation of the cost function: output, complexity of provided services (case-mix), input prices. The full sample is a panel of 29 productive units which are observed over a period of 5 years, for a total of 145 observations. As an index of production volume $(Y)$ we opted for the total number of patients per year (both inpatients and outpatients). We included both types of patients to take into account the increase observed in the last decade in the share of outpatients out of total patients; this solves also the omitted variable bias emphasised by Crémieux and Ouellette for hospital cost functions $(2001)^{4}$. In addition, in order to keep into account

\footnotetext{
${ }^{4}$ We also tested in our cost model a variable controlling for the ratio of outpatients to the total number of patients. As the coefficient associated to this variable turned out to be statistically insignificant, we decided to drop it in the following analysis.
} 
the severity of illnesses and the composition of our output measure, a control variable of the average DRG weight $(D R G W)$ has been added. Such a variable should reflect the differences in the production mix, i.e. the average degree of complexity of the services provided by the hospital structures ${ }^{5}$.

As the labour input is concerned, a distinction has been made between medical staff ( $M S$, including physicians and nurses) and administrative staff $(A S)$; the average price for the two categories ( $P_{M S}$ and $P_{A S}$, respectively) has been obtained by dividing costs by the effective number of employees. As a proxy for the price of drugs $\left(P_{D}\right)$ we used the ratio between the corresponding cost and the total number of inpatients and outpatients days per year. Finally, as common in the literature, the average price of the capital input $\left(P_{K}\right)$ has been computed by dividing depreciation costs by the total number of beds (e.g., Jacobs et al., 2006, for general comments and a survey). Admittedly, this is only a crude measure of capital usage in the production of hospital services; however, this is just the policy variable we are interested in assessing substitution possibilities.

A time trend that should capture the effect of technical progress has been added to the model (TREND). Its coefficient can be interpreted as a growth (or reduction) rate of costs due to an Hicks-neutral technological change.

Table 2 reports the descriptive statistics of the variables used in the estimation. There is a high variability in the level of operating costs and in the output levels, which is partially due to the fact that our sample of hospitals is very heterogeneous in size, but can be also explained by the above mentioned differences among ASL and AO units ${ }^{6}$.

\footnotetext{
${ }^{5}$ For example, a tonsillectomy is a typical operation with a low degree of complexity (DRG weight 0.27 ), while thyroid (DRG weight 1.04) and cardiovascular operations (DRG weight 2.40) have an average and a high degree of complexity, respectively.

${ }^{6}$ The sample consists of 7 small units (average number of beds $\left.\leq 368\right), 15$ units of an average size $(368<$ average number of beds $\leq 621$ ) and 7 big units (average number of beds $>621$ ). It is important to note
} 
[TABLE 2 HERE]

\subsection{Functional form and estimation procedure}

The bulk of empirical works on hospital costs adopted the well-known Translog specification. Given the complexity of hospital services production process, we do not impose a priori restrictions on the functional form and estimate a more general model, namely the Generalised Composite cost function, which has been first introduced by Pulley and Braunstein $\left(1992, \mathrm{~PB}_{\mathrm{G}}\right)$. The $\mathrm{PB}_{\mathrm{G}}$ model reads as follows:

$$
\begin{aligned}
& O H C^{(\phi)}=\left\{\exp \left[\begin{array}{l}
\alpha_{0}+\alpha_{Y} Y^{(\pi)}+\alpha_{\text {DRGW }} D R G W^{(\pi)}+\frac{1}{2} \alpha_{Y Y} Y^{(\pi)} Y^{(\pi)}+\frac{1}{2} \alpha_{\text {DRGWDRGW }} D R G W^{(\pi)} D R G W^{(\pi)} \\
+\alpha_{Y D R G W} Y^{(\pi)} D R G W^{(\pi)}+\sum_{r} \delta_{Y r} Y^{(\pi)} \ln P_{r}+\sum_{r} \delta_{\text {DRGW }} D R G W^{(\pi)} \ln P_{r}
\end{array}\right]\right. \\
&\left.\cdot \exp \left[\sum_{r} \beta_{r} \ln P_{r}+\frac{1}{2} \sum_{r} \sum_{l} \beta_{r l} \ln P_{r} \ln P_{l}\right]\right\}
\end{aligned}
$$

where the superscripts in parentheses $\pi, \phi$ and $\tau$ represent Box-Cox transformations (for example $Y^{(\pi)}=\left(Y^{\pi}-1\right) / \pi$ for $\pi \neq 0$ and $Y^{(\pi)} \rightarrow \ln Y$ for $\left.\pi \rightarrow 0\right) . O H C$ is the long-run production cost of hospital services, $Y$ is the output, $D R G W$ is the average degree of complexity of the service provided, and $P_{r}$ indicates factor prices (with $r=M S, A S, D$ and $K$ ). By applying the Shephard's Lemma, the associated input cost-share equations are:

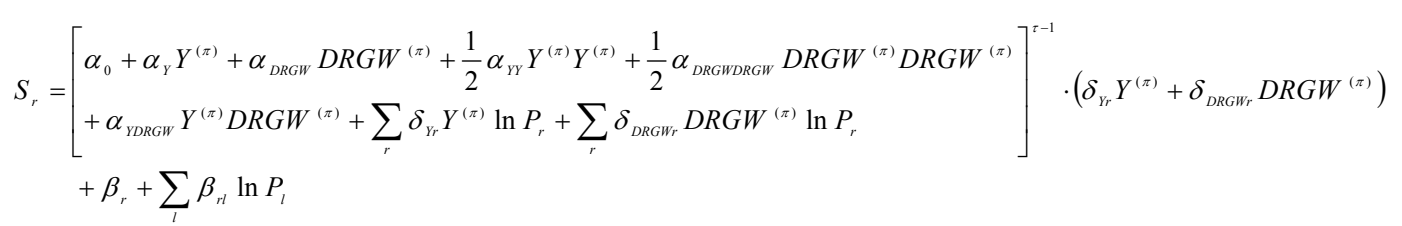

that results are unaffected by the choice of pooling together ASL and AO. In particular, our conclusions hold also estimating the models only on the ASL sub-sample. 
The Composite specification $\left(\mathrm{PB}_{\mathrm{C}}\right)$ is obtained by setting $\pi=1$ and $\tau=0$. In a similar vein, the well-known Generalised Translog (GT) and Standard Translog (ST) models, as well as the Separable Quadratic (SQ) functional form, can be estimated by imposing simple restrictions on the system (1)-(2)

The PB cost functions originate from the combination of the log-quadratic input price structure of the ST and GT specifications with a quadratic structure for outputs. ${ }^{8}$ The relatively few studies which employed the PB specifications referred to the banking, telecommunications, multi-utilities and electricity sectors. Overall, the composite model has consistently proved to be successful in obtaining more stable and reliable estimates than the alternative functional forms (see Piacenza and Vannoni, 2004, for more details). The $\mathrm{PB}_{\mathrm{G}}$ model proposes to transform both sides of the cost function - from $O H C=C(Y, P)$ to $O H C^{(\phi)}=[C(Y, P)]^{(\phi)}-$ in order to enlarge the set of plausible empirical specifications. The optimal value of $\phi$ can be estimated resorting to non-linear least squares routines. The comparison between the general $\mathrm{PB}_{\mathrm{G}}$ specification and the nested models (i.e. $\mathrm{PB}_{\mathrm{C}}, \mathrm{SQ}, \mathrm{GT}$, and $\mathrm{ST}$ ) can be made by LR tests using the estimated log-likelihood values for the system (1)-(2).

\footnotetext{
${ }^{7}$ More precisely, the GT model is obtained by setting $\phi=0$ and $\tau=1$, while the ST model requires the further restriction $\pi=0$. The SQ model is obtained from the $\mathrm{PB}_{\mathrm{C}}$ specification by adding the restrictions $\delta_{Y r}=0$ and $\delta_{D R G W r}=0$ for all $r$.

${ }^{8}$ The log-quadratic input price structure can be easily constrained to be linearly homogeneous. To be consistent with cost minimization, (1) must satisfy symmetry $\left(\beta_{r l}=\beta_{l r}\right.$ for all couples $\left.r, l\right)$ as well as the following properties: $a$ ) non-negative fitted costs; $b$ ) non-negative fitted marginal costs with respect to outputs; $c)$ homogeneity of degree one of the cost function in input prices $\left(\Sigma_{r} \beta_{r}=1\right.$ and $\Sigma_{l} \beta_{r l}=0$ for all $r$, as well as $\Sigma_{r} \delta_{Y r}=0$ and $\left.\Sigma_{r} \delta_{D R G W r}=0\right) ; d$ ) non-decreasing fitted costs in input prices; $e$ ) concavity of the cost function in input prices.
} 
All the specifications of the cost function are estimated jointly with their associated input cost-share equations. In our four-inputs case, to avoid the singularity of the covariance matrix of residuals, the equation for administrative staff $\left(S_{A S}\right)$ was not included in each of the estimated systems. Prior to estimation, all variables were standardized on their respective sample means. Parameter estimates were obtained via a non-linear GLS estimation (NLSUR), which ensures estimated coefficients to be invariant with respect to the omitted share equation.

\subsection{Results: the cost function}

The results of the NLSUR estimation for the ST, GT, SQ, and PB models are presented in table 3. By looking at the summary statistics (last five rows), one can observe that computed $R^{2}$ for the cost function is rather high and identical across specifications, while $R^{2}$ associated to the factor-share equations are not dissimilar except from the SQ model, for which are much lower (in particular for capital input). The poor ability of the SQ specification to fit the observed factor-shares is not surprising, given that it assumes a strong separability between inputs and outputs. McElroy's (1977) $R^{2}$ can be used as a measure of the general goodness of fit for the NLSUR system. The results suggest that the fit is almost identical for the different functional forms, and between $83 \%$ and $86 \%$. However, LR tests comparing $\mathrm{PB}_{\mathrm{G}}$ and the restricted specifications (see table 4) always lead to favour the Generalised Composite model (at the 5\% significance level) with respect to $\mathrm{PB}_{\mathrm{C}}, \mathrm{SQ}, \mathrm{GT}$, and $\mathrm{ST}$ alternative functional forms.

\section{[TABLE 3 AND 4 HERE]}

The first six rows of table 3 present the estimates of first-order coefficients for output, average DRG weight and factor prices, which are all highly significant and show the 
expected sign. Since the results are similar across specifications, we comment only on the estimated parameters for the $\mathrm{PB}_{\mathrm{G}}$ model, which is to be preferred over the alternatives according to LR tests. In particular, we briefly discuss cost elasticities with respect to $Y, D R G W, P_{M S}, P_{D}$ and $P_{K}$ for the average hospital within the industry ${ }^{9}$.

As for the output elasticity, the estimate is significantly lower than 1 (around 0.71, Standard Error 0.05), revealing the presence of remarkable scale economies (index of returns to scale about 1.41 , SE 0.11 ) that could be better exploited, for instance, by enlarging the average size of hospitals managed by LHUs. On the $D R G W$ side, it emerges a strong impact of the severity of illnesses on $O H C$ (about 0.39, SE 0.13), which is consistent with previous empirical literature on the cost structure of hospital services. Finally, as for the estimates of input cost-shares for the average hospital corresponding to cost elasticities with respect to the price of medical staff (0.66), drugs (0.10), and capital, proxied by beds (0.05) - they are very similar to their respective sample mean values (see $S_{M S}, S_{D}$ and $S_{K}$ in table 2), thus confirming the general goodness of fit of the $\mathrm{PB}_{\mathrm{G}}$ cost function model.

\subsection{Results: the elasticities of substitution}

Definitions. Given the main aim of this study, we computed Allen, Morishima, and Shadow elasticities of substitution for all the estimated models (Chambers, 1988). Ideally, one wants to measure for each couple of inputs the percentage change in the input ratio $x_{r} / x_{l}$ due to a percentage change in the input price ratio $P_{l} / P_{r}$. Allen elasticities can be considered as one price-one factor elasticities, since they measure how the use of an input varies due to changes in the price of another input. They can be computed as $\sigma_{r l}^{A}$ $=\varepsilon_{r l} / S_{l}$, where $S_{l}$ is the $l^{t h}$ cost share and $\varepsilon_{r l}$ is the derived input-demand elasticity of input

\footnotetext{
${ }^{9}$ The average LHU (the point of normalization) corresponds to a hypothetical LHU operating at an average level of production and degree of complexity, and facing average input prices.
} 
$x_{r}$ with respect to price $P_{l}\left(\mathrm{~d} \ln x_{r} / \mathrm{d} \ln P_{l}\right)$. While they have been criticized to a great extent in the literature, Allen elasticities are still widely used in applied production analysis as they serve as the basis for deriving other elasticities. Morishima elasticities represent two factor-one price elasticities and are closer proxies to the desirable measure. They are computed as $\sigma_{r l}^{M}=\varepsilon_{r l}-\varepsilon_{l l}$ and measure how the $r, l$ input ratio responds to a change in $P_{l}$. There is a useful link between Morishima and Allen elasticities:

$$
\sigma_{r l}^{M}=\left(\sigma_{r l}^{A}-\sigma_{l l}^{A}\right) S_{l}
$$

It is straightforward to notice than when inputs are Allen substitutes, they must be also Morishima substitutes (since $\sigma_{l l}^{A}$ is always negative) but the converse does not hold, so that inputs can well be Allen complements and Morishima substitutes. Finally, Shadow elastiticities of substitution are a weighted average of Morishima elasticities and, as such, they are two factor-two price elasticities:

$$
\sigma_{r l}^{S}=\frac{S_{r}}{S_{r}+S_{l}} \sigma^{M}{ }_{r l}+\frac{S_{l}}{S_{r}+S_{l}} \sigma^{M}{ }_{r r}
$$

After some computation, Allen elasticities can be written as:

$$
\sigma_{r l}^{A}=\frac{\frac{\partial S_{r}}{\partial P_{l}} P_{l}+S_{r} S_{l}}{S_{r} S_{l}}
$$

Thus, in order to compute such elasticities for our different cost function models, it is important to compute the partial derivative $\partial S_{r} / \partial \ln P_{l .}{ }^{10}$

[TABLE 5 HERE]

\footnotetext{
${ }^{10}$ In the ST, GT and SQ specifications, such derivative trivially corresponds to the coefficient $\beta_{r l}$, while in the other two specifications $\left(\mathrm{PB}_{\mathrm{G}}\right.$ and $\left.\mathrm{PB}_{\mathrm{C}}\right)$ its computation is much more complicated, as it can be seen from a close inspection of equation (2).
} 
Empirical evidence. As can be seen in table 5, except from Allen elasticities for the input pair drugs-capital, all inputs are substitutes, but the low estimated values suggest that substitution possibilities are in general very limited. As an example, in the $\mathrm{PB}_{\mathrm{G}}$ specification, $\sigma^{M}{ }_{M S, K}=0.13$, suggesting that a $10 \%$ increase in the price of capital implies only a $1.3 \%$ change in the $M S / K$ ratio. The highest figures are recorded for the input pairs involving $A S$, suggesting that the other three inputs (medical staff, drugs and capital) are particularly responsive to increases in the price of administrative staff $\left(\sigma_{r, A S}^{M}\right.$ are higher than $\sigma_{A S, r}^{M}$ for all $r$ ). The results are remarkably stable across specifications for almost all input pairs, and are broadly consistent with the ones previously appeared in the empirical literature. As discussed in Section 2, e.g. Jensen and Morrisey (1986) found substitution elasticities equal to 0.25 for the pair medical staff/beds and equal to 0.19 for the pair nurses/beds. Bilodeau et al. (2002) found that labour and drugs were substitutes with substitution elasticities lower than 1 . As far as capital is concerned, the substitution possibilities with other inputs are lower, i.e. the values of $\sigma_{r, K}^{M}$ are lower than all the other $\sigma_{r, l}^{M}$ couples and the values of $\sigma_{K, r}^{M}$ are lower than all the other $\sigma_{l, r}^{M}$ couples.

[TABLE 6 HERE]

Discussion. Table 6 presents the estimates of Shadow elasticities of input substitutability when the productive scale $(Y)$ and the DRG weight $(D R G W)$ of the average hospital of our sample are increased (and reduced) proportionally, focusing on the cost function model best fitting the data, i.e. the $\mathrm{PB}_{\mathrm{G}}$ specification. Parameters $\lambda_{Y}$ and $\lambda_{D R G W}$ refer to the coefficients used to scale down $\left(\lambda_{Y}=0.25,0.5 ; \lambda_{D R G W}=0.5\right)$ and up $\left(\lambda_{Y}=2,3 ; \lambda_{D R G W}\right.$ 
$=2)$ the average values of the output ( $Y=22,072$ patients) and DRG weight ( $D R G W=$ 1.12), respectively ${ }^{11}$. First, notice that for almost all input pairs (with the notable exception of $M S-A S)$, it emerges a certain degree of complementarity only by scaling down the average producer. Even if estimated elasticities are always insignificant at the usual confidence levels, this result suggests a higher rigidity in managing inputs for small-scale low-complexity generalist community hospitals, for instance because they need to respect exogenously given standards for staff and beds, which are binding given their volumes of output. Clearly enough, this rigidity helps explain the findings of unexploited scale economies for very small hospitals. Second, note that by scaling up the average hospital, both with respect to output volume and with respect to output complexity, substitution possibilities (and statistical significance) increase, but substitutability remain fairly small and significantly less than unity. These results hold even scaling up contemporaneously the average hospital in the two mentioned directions. For instance, concentrating on the most interesting of these input pairs for us $(M S-K)$, by doubling the DRG weight and tripling output volume, elasticity of substitution rises from 0.14 to 0.30 only. Notice also that - for the $M S-K$ pair - holding constant output volume at $\lambda_{Y}=3$, it emerges a slight decrease of substitution possibilities when increasing complexity of output. This last result shows up also for almost all other couples of inputs, and suggests that - at high volumes - substitution between factors becomes increasingly difficult when also complexity of treated patients increase. This finding is consistent with a high rigidity of the production process starting from high levels of output. Results are more ambiguous when holding DRG weights fixed at $\lambda_{D R G W}=2$ : increasing the levels of output eases substitutability for the $M S-K, D-K$, and $K-A S$ pairs, while substitutability worsens for the remaining couples of inputs. Finally, note that for

\footnotetext{
${ }^{11}$ Notice that scale parameters are based on values of $Y$ and $D R G W$ observed in our sample.
} 
the $M S$ - $A S$ input pair, estimated elasticities are invariant both to scaling with respect to output volume and to scaling with respect to output complexity, being consistently close to unity (and statistically significant). Besides showing that these two inputs are the more substitutable in the production process of hospitals, this result suggests that Administrative Staff is not probably a source of production economies. Overall, our findings confirms then previous estimates in the literature, validating the difficulties for hospitals in substituting between input pairs, in particular between medical staff and beds.

These difficulties cast some doubts on bed downsizing policies as an effective tool for controlling health expenditure in countries, like the European ones, where the share of public producers (and public funding) is significantly higher than in the U.S. Restructuring of the hospital industry limited to reductions in the number of beds, without tackling the likely presence of excessive staffing, can both bound the production possibilities and - more importantly -preclude potential savings in health expenditure.

Notice that our results can be affected by two potential sources of distortions. On the one hand, since we estimate a cost function, we use the implicit assumption of cost minimization. By taking into account the cost inefficiency in the provision of health care services, how will the results on input substitutability be affected? Unfortunately, we are unable to estimate jointly a system of cost functions and related cost share equations in a stochastic frontier framework. Without the inclusion of the information on input cost shares the results coming from one equation frontier models, as far as input substitutability is concerned, are in generally very poor. However, some past studies found that there are no substantial differences among technological estimates coming from average and frontier cost functions for hospitals (e.g. Eakin and Kniesner, 1988). The second issue is that, even if one remains confined within a cost function analysis, 
our sample of firms is affected by a regulatory intervention aimed at hospital downsizing by means of the reduction in the number of beds. In particular, the constraints are imposed by the Central government at the regional level (i.e., the target of reducing the number of beds must be reached for the whole Piedmont region), so that one cannot include the constraint in the specification of the cost function (which refer to the hospital level). However, again, the presence of this constraint is not seriously biasing the estimates for input elasticities. For example, Granderson and Lovell (1998) were able to introduce a firm-specific variable accounting for rate of return regulation in the gas industry and found that such regulation increased the estimates of elasticity of substitution of $\sigma_{K, r}^{M}$ pairs and reduced those of $\sigma_{r, K}^{M}$ pairs. Since in our case the constraint pushes toward the reduction of beds, it is reasonable to assume that in an unregulated framework one should observe higher values for $\sigma_{r, K}^{M}$ couples and lower values for $\sigma_{K, r}^{M}$ pairs. Looking at the figures in table 5, this means that the values of such pairs should get closer the ones to the others, thus making Morishima elasticities more symmetrical and leaving almost unchanged the values of Shadow elasticities.

\section{Concluding remarks}

The hospital industry in many countries has undergone an unprecedented process of restructuring, aimed at reducing excess capacity and increasing the appropriateness of care. In Italy (like in other European countries) this process has been limited to bed downsizing; the management and planning of the workforce potentially in excess has been conducted using fixed-ratio relationships with no empirical validity, often resulting in a change of the input-mix used in the production of hospital services.

In this paper, starting from the premise that industry restructuring is - at least partly - aimed at controlling expenditure growth, we investigate the economic rationality of input-mix change, providing fresh evidence on the factor substitutions characterising 
hospitals' technology. We consider all producers located in Piedmont, a region in the North-Western part of Italy, where the hospital industry has been (and still is) marked by a wide reduction in the number of beds, while no significant decrease has been observed for medical staff (including both physicians and nurses). Differently from other studies, we do not impose a priori restrictions on the specification of the hospital cost function, and estimate a more general model, namely the Generalised Composite, embracing all the standard specifications usually adopted in the literature. For all the models, we derive Allen, Morishima and Shadow elasticities of substitution between input pairs, obtaining a fairly consistent picture across all specifications and elasticity concepts. In particular, confirming previous findings in the literature, our results suggest a very limited degree of substitutability between factors in the production of hospital services. This is particularly true for beds and medical staff.

Given this evidence, one can notice that putting restrictions on bed capacity without taking into account their limited possibility of substitution - might imply an inefficient use of resources, and severely limit the possibility to control public health expenditure by restructuring the hospital industry. More effective policies are probably needed to obtain the expected savings. An example in this direction is likely to be the reallocation of the workforce from the hospital towards the production of other health care services. 


\section{References}

Aiken L. H., Clarke S., Sloane D. (2002a), Hospital Staffing, Organization, and Quality of Care: Cross-National Findings, International Journal for Quality in Health Care, 14 (1), 5-13.

Aiken L. H., Clarke S., Sloane D., Sochalski J., Silber J. H. (2002b), Hospital Nurse Staffing and Patient Mortality, Nurse Burnout and Job Dissatisfaction, Journal of the American Medical Association, 288 (16), 1987-1993.

Bilodeau D., Crèmieux P.-Y., Ouellette P. (2002), Hospital Technology in a Nonmarket Health Care System, Southern Economic Journal, 68 (3), 511-529.

Birkmeyer N. J., Siewers A. E., Finlayson E. V. A., Stukel T. A., Lucas F. L., Batista I., Welch G. H., Wennberg D. E. (2002), Hospital Volume and Surgical Mortality in the United States, New England Journal of Medicine, 346 (15), 1128-1137.

Bloor K., Maynard A. (2003), Planning Human Resources in Health Care: Towards an Economic Approach. An International Comparative View, Canadian Health Services Research Foundation.

Bothwell J. L., Cooley T. F. (1982), Efficiency in the Provision of Health Care: An Analysis of Health Maintenance Organizations, Southern Economic Journal, 48 (4), 970-984.

Chadwick C., Hunter L. W., Walston S. L. (2004), Effects of Downsizing Practices on the Performance of Hospitals, Strategic Management Journal, 25, 405-427.

Chambers R. G. (1988), Applied Production Analysis: A Dual Approach, Cambridge University Press. 
Cowing T., Holtmann A. (1983), Multiproduct Short-run Hospital Cost Functions: Empirical Evidence and Policy Implications from Cross-section Data, Southern Economic Journal, 49 (3), 637-653.

Crèmieux P.-Y., Ouellette P. (2001), Omitted variable bias and hospital costs, Journal of Health Economics, 20, 271-282.

Eakin B. K., Kniesner T. J. (1988), Estimating a Non-minimum Cost Function for Hospitals, Southern Economic Journal, 54 (3), 583-597.

France G., Taroni F., Donatini A. (2005), The Italian Health-Care System, Health Economics, 14, 187-202.

Gerdtham U.-G., Jönsson B. (2000), International Comparisons of Health Expenditure, in Culyer A. J. and Newhouse J. P., Handbook of Health Economics, Amsterdam: North-Holland, vol. 1A, 11-53.

Granderson G., Lovell K. C. A. (1998), The Impact of Regulation on Input Substitution and Operating Cost, Southern Economic Journal, 65 (1), 83-97.

Grilli R., Minozzi S., Tinazzi A., Labianca R., Sheldon T. A., Liberati A. (1998), Do Specialist Do It Better? The Impact of Specialization on the Processes and Outcomes of Care for Cancer Patients, Annals of Oncology, 9, 365-374.

Hensher M., Edwards N., Stokes R. (1999), International Trends in the Provision and Utilisation of Hospital Care, British Medical Journal, 319, 845-848.

Jacob R., Smith P. C., Street A. (2006), Measuring Efficiency in Health Care, Cambridge: Cambridge University Press.

Jensen G. A., Morrisey M. A. (1986), The Role of Physicians in Hospital Production, Review of Economics and Statistics, 68 (3), 432-442. 
Kroneman M., Siegers J.J. (2004), The Effect of Hospital Bed Reduction on the Use of Beds: A Comparative Study of 10 European Countries, Social Science and Medicine, 59, 1731-1740.

McElroy M. (1977), Goodness of Fit for Seemingly Unrelated Regressions: Glahn's and Hooper's, Journal of Econometrics, 6, 381-387.

Piacenza M., Vannoni D. (2004), Choosing among Alternative Cost Function Specifications: An Application to Italian Multi-utilities, Economics Letters, 82 (3), $410-417$.

Posnett J. (1999), Is Bigger Better? Concentration in the Provision of Secondary Care, British Medical Journal, 319, 1063-1065.

Preyra C., Pink G. (2006), Scale and Scope Efficiencies through Hospital Consolidations, Journal of Health Economics, 25, 1049-1068.

Propper C. (2001), Expenditure on Health Care in the UK: A Review of the Issues, Fiscal Studies, 22 (2), 151-183.

Pulley L. B., Braunstein Y. M. (1992), A Composite Cost Function for Multiproduct Firms with an Application to Economies of Scope in Banking, Review of Economics and Statistics, 74, 221-230. 
Table 1. Breakdown of operating hospital costs (OHC) for ASL and AO (average 2000-2004)

\begin{tabular}{lcc}
\hline & ASL & AO \\
\hline \hline Labour & $87.6 \%$ & $84.7 \%$ \\
$\quad$ Medical Staff & $67.4 \%$ & $64.8 \%$ \\
Drugs & $8.5 \%$ & $10.6 \%$ \\
Depreciation & $3.9 \%$ & $4.7 \%$ \\
Operating hospital costs $\left(10^{3} €\right)$ & 78,628 & 121,558 \\
\hline
\end{tabular}


Table 2. Descriptive Statistics

\begin{tabular}{l|rrrrr}
\hline & Mean & St. Dev. & Min & Median & Max \\
\cline { 2 - 6 } Operating Hospital Cost $\left(10^{3} €\right)$ & & & & & \\
Labor + Drugs + Capital cost & 88,990 & 42,985 & 29,262 & 86,495 & 309,694 \\
\hline \hline Production data & & & & & \\
Total number of patients $(Y)$ & 22,072 & 13,237 & 639 & 19,728 & 68,715 \\
Average DRG weight $(D R G W)$ & 1.12 & 0.20 & 0.64 & 1.06 & 1.93 \\
\hline \hline Input prices & & & & & \\
Medical Staff $(€$ per MS worker) & 46,181 & 2,133 & 41,665 & 46,319 & 55,572 \\
Administrative Staff $(€$ per $A S$ worker) & 26,544 & 1,841 & 22,053 & 26,310 & 31,170 \\
Drugs (€ per day) & 63 & 31 & 21 & 57 & 200 \\
Capital $(€$ per bed) & 8,051 & 3,715 & 3,016 & 7,170 & 22,859 \\
\hline \hline Input cost-shares & & & & & \\
Medical Staff $\left(S_{M S}\right)$ & 0.67 & 0.04 & 0.57 & 0.67 & 0.75 \\
Administrative Staff $\left(S_{A S}\right)$ & 0.20 & 0.03 & 0.14 & 0.20 & 0.30 \\
Drugs $\left(S_{D}\right)$ & 0.09 & 0.03 & 0.03 & 0.09 & 0.20 \\
Capital $\left(S_{K}\right)$ & 0.04 & 0.01 & 0.02 & 0.04 & 0.09 \\
\hline
\end{tabular}


Table 3. NLSUR parameter estimates for the Generalised Composite $\left(\mathrm{PB}_{\mathrm{G}}\right)$, Composite $\left(\mathrm{PB}_{\mathrm{C}}\right)$, Separable Quadratic (SQ), Generalised Translog (GT) and Standard Translog (ST) models

\begin{tabular}{|c|c|c|c|c|c|}
\hline REGRESSORS $^{a}$ & $\mathrm{~PB}_{\mathrm{G}}$ MODEL & $\mathrm{PB}_{\mathrm{C}}$ MODEL & SQ MODEL & GT MODEL & ST MODEL \\
\hline Constant & $1.004^{\star \star \star}$ & $0.995^{\star \star \star}$ & $1.003^{\star \star \star}$ & -0.021 & $0.982^{\star \star \star}$ \\
\hline$Y$ & $0.717^{\star \star \star}$ & $0.638^{\star \star \star}$ & $0.683^{\star \star \star}$ & $0.622^{\star \star \star}$ & $0.638^{\star \star \star *}$ \\
\hline DRGW & $0.391^{* \star *}$ & $0.479 * \star *$ & $0.553^{\star \star \star}$ & $0.367^{\star * *}$ & $0.441^{\star * *}$ \\
\hline $\ln P_{M S}$ & $0.658^{\star \star \star}$ & $0.658^{\star \star \star}$ & $0.661^{\star \star \star}$ & $0.660 * \star \star$ & $0.658^{\star \star \star}$ \\
\hline $\ln P_{D}$ & $0.100^{\star * *}$ & $0.101^{\star * *}$ & $0.095^{\star \star \star}$ & $0.098^{\star * *}$ & $0.100^{\star \star *}$ \\
\hline $\ln P_{K}$ & $0.046^{\star \star \star}$ & $0.046^{\star \star *}$ & $0.043^{\star \star *}$ & $0.044^{\star * *}$ & $0.046^{\star \star \star}$ \\
\hline TREND & 0.003 & 0.002 & 0.004 & 0.011 & 0.008 \\
\hline$Y^{2}$ & -0.321 & -0.113 & $-0.136^{\star \star}$ & -0.241 & $0.187^{\star}$ \\
\hline$D R G W^{2}$ & 0.322 & 0.031 & 0.002 & -0.141 & -0.560 \\
\hline YDRGW & 0.526 & $0.613^{\star * *}$ & $0.587^{\star \star *}$ & 0.272 & 0.214 \\
\hline$Y \ln P_{M S}$ & -0.013 & -0.011 & 0 & $-0.016^{\star}$ & -0.010 \\
\hline$Y \ln P_{D}$ & $0.019 * * *$ & $0.018^{\star \star *}$ & 0 & $0.021^{\star * *}$ & $0.017^{* * *}$ \\
\hline$Y \ln P_{K}$ & $0.012^{\star \star}$ & $0.011^{\star \star}$ & 0 & $0.012^{\star \star}$ & $0.010^{\star}$ \\
\hline$D R G W \ln P_{M S}$ & $-0.025^{\star *}$ & $-0.024^{\star}$ & 0 & $-0.035^{\star \star}$ & $-0.034^{\star *}$ \\
\hline$D R G W \ln P_{D}$ & $0.037^{* * *}$ & $0.037^{* * *}$ & 0 & $0.048^{* * *}$ & $0.048^{\star * *}$ \\
\hline$D R G W \ln P_{K}$ & 0.012 & 0.012 & 0 & 0.015 & 0.015 \\
\hline $\ln P_{M S} P_{A S}$ & 0.010 & 0.007 & -0.004 & 0.005 & 0.006 \\
\hline $\ln P_{M s} P_{D}$ & $-0.046^{\star \star \star}$ & $-0.046^{\star \star *}$ & $-0.043^{\star * \star}$ & $-0.044^{\star \star \star}$ & $-0.044^{* \star *}$ \\
\hline $\ln P_{M s} P_{K}$ & 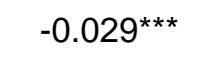 & $-0.028^{\star \star \star}$ & $-0.023^{\star * \star}$ & $-0.027^{\star \star *}$ & $-0.027^{\star \star \star}$ \\
\hline $\ln P_{A s} P_{D}$ & -0.010 & -0.009 & 0.001 & -0.004 & -0.006 \\
\hline $\ln P_{A s} P_{K}$ & 0.004 & 0.002 & 0.007 & 0.006 & 0.003 \\
\hline $\ln P_{D} P_{K}$ & $-0.012^{\star \star}$ & $-0.012^{\star * *}$ & $-0.017^{\star \star *}$ & $-0.014^{\star \star \star}$ & $-0.013^{\star * *}$ \\
\hline$B o x-\operatorname{Cox} \phi$ & $-0.446^{*}$ & -0.260 & -0.260 & 0 & 0 \\
\hline Box-Cox $\pi$ & $1.219 * * *$ & 1 & 1 & $0.563^{\star \star *}$ & 0 \\
\hline Box-Cox $\tau$ & 0.015 & 0 & 0 & 1 & 1 \\
\hline System log-likelihood & 1406.581 & 1402.422 & 1315.912 & 1385.590 & 1377.424 \\
\hline System $R^{2 \mathrm{~b}}$ & 0.863 & 0.859 & 0.832 & 0.849 & 0.858 \\
\hline - Cost function $R^{2}$ & 0.921 & 0.918 & 0.916 & 0.918 & 0.916 \\
\hline - $S_{M S}$ equation $R^{2}$ & 0.514 & 0.507 & 0.446 & 0.528 & 0.512 \\
\hline - $S_{D}$ equation $R^{2}$ & 0.769 & 0.771 & 0.581 & 0.766 & 0.782 \\
\hline - $S_{K}$ equation $R^{2}$ & 0.571 & 0.592 & 0.073 & 0.518 & 0.570 \\
\hline
\end{tabular}

\footnotetext{
${ }^{a}$ The dependent variable is Operating Hospital Costs $(\mathrm{OHC})$.

b The goodness-of-fit measure used for NLSUR systems is McElroy's (1977) $R^{2}$.

${ }^{\star * \star}$ significant at $1 \%$ level, ${ }^{* *}$ significant at $5 \%$ level, * significant at $10 \%$ level (two-tailed test).
} 
Table 4. Comparing Generalised Composite $\left(\mathrm{PB}_{\mathrm{G}}\right)$ against restricted models by $\mathrm{LR}$ tests

\begin{tabular}{l|rc}
\hline${\text { Restricted } \text { model }^{\mathrm{a}}}$ & $\chi^{2}$-statistic & P-value \\
\hline \hline PB & 8.318 & 0.016 \\
SQ MODEL $(\pi=1, \tau=0)$ & 181.338 & 0.000 \\
GT MODEL $(\phi=0, \tau=1)$ & 41.983 & 0.000 \\
ST MODEL $(\phi=0, \pi=0, \tau=1)$ & 58.314 & 0.000 \\
\hline
\end{tabular}

${ }^{\mathrm{a}}$ The restrictions with respect to $\mathrm{PB}_{\mathrm{G}}$ model are reported in parentheses. 
Table 5. Estimates of input substitutability elasticities (at mean values of output, average DRG weight and input prices) for different cost function models ${ }^{\mathrm{a}}$

\begin{tabular}{|c|c|c|c|c|c|}
\hline $\begin{array}{l}\text { Allen elasticities } \\
\text { (1 factor, } 1 \text { price) }\end{array}$ & $\mathrm{PB}_{\mathrm{G}}$ MODEL & $\mathrm{PB}_{\mathrm{C}}$ MODEL & SQ MODEL & GT MODEL & ST MODEL \\
\hline$M S, K$ & $0.02(0.27)$ & $0.09(0.25)$ & $0.17(0.25)$ & $0.06(0.26)$ & $0.10(0.26)$ \\
\hline$M S, D$ & $0.31(0.13)$ & $0.31(0.12)$ & $0.32(0.12)$ & $0.31(0.12)$ & $0.33(0.13)$ \\
\hline$M S, A S$ & $1.08(0.30)$ & $1.05(0.30)$ & $0.87(1.23)$ & $1.04(0.28)$ & $1.05(0.30)$ \\
\hline$D, K$ & $-1.62(1.16)$ & $-1.56(1.01)$ & $-3.30(0.59)$ & $-2.26(0.85)$ & $-1.94(1.00)$ \\
\hline$D, A S$ & $0.50(0.57)$ & $0.52(0.54)$ & $1.06(0.38)$ & $0.78(0.47)$ & $0.67(0.53)$ \\
\hline$K, A S$ & $1.39(1.33)$ & $1.22(1.18)$ & $1.85(0.95)$ & $1.66(1.06)$ & $1.38(1.22)$ \\
\hline $\begin{array}{l}\text { Morishima elasticities } \\
\text { (2 factors, } 1 \text { price) }\end{array}$ & $\mathrm{PB}_{\mathrm{G}}$ MODEL & $\mathrm{PB}_{\mathrm{C}}$ MODEL & SQ MODEL & GT MODEL & ST MODEL \\
\hline$M S, K$ & $0.13(0.13)$ & $0.14(0.11)$ & $0.18(0.10)$ & $0.15(0.11)$ & $0.15(0.12)$ \\
\hline$K, M S$ & $0.26(0.18)$ & $0.30(0.17)$ & $0.34(0.17)$ & $0.28(0.18)$ & $0.31(0.18)$ \\
\hline$M S, D$ & $0.26(0.05)$ & $0.20(0.05)$ & $0.31(0.06)$ & $0.29(0.06)$ & $0.29(0.06)$ \\
\hline$D, M S$ & $0.45(0.09)$ & $0.44(0.09)$ & $0.44(0.09)$ & $0.45(0.09)$ & $0.46(0.09)$ \\
\hline$M S, A S$ & $1.04(0.28)$ & $1.01(0.28)$ & $1.00(0.43)$ & $1.03(0.26)$ & $1.02(0.28)$ \\
\hline$A S, M S$ & $0.95(0.25)$ & $0.93(0.25)$ & $0.81(0.86)$ & $0.92(0.24)$ & $0.93(0.25)$ \\
\hline$D, K$ & $0.05(0.10)$ & $0.07(0.11)$ & $0.03(0.11)$ & $0.05(0.12)$ & $0.05(0.12)$ \\
\hline$K, D$ & $0.06(0.13)$ & $0.08(0.08)$ & $-0.03(0.07)$ & $0.04(0.08)$ & $0.06(0.08)$ \\
\hline$D, A S$ & $0.92(0.29)$ & $0.90(0.28)$ & $1.04(0.22)$ & $0.99(0.25)$ & $0.95(0.29)$ \\
\hline$A S, D$ & $0.28(0.09)$ & $0.29(0.09)$ & $0.38(0.08)$ & $0.34(0.09)$ & $0.33(0.09)$ \\
\hline$K, A S$ & $1.10(0.40)$ & $1.04(0.38)$ & $1.20(0.29)$ & $1.16(0.32)$ & $1.09(0.38)$ \\
\hline$A S, K$ & $0.19(0.18)$ & $0.16(0.15)$ & $0.25(0.13)$ & $0.22(0.14)$ & $0.20(0.17)$ \\
\hline $\begin{array}{l}\text { Shadow elasticities } \\
\text { (2 factors, } 2 \text { prices) }\end{array}$ & $\mathrm{PB}_{\mathrm{G}}$ MODEL & $\mathrm{PB}_{\mathrm{C}} \mathrm{MODEL}$ & SQ MODEL & GT MODEL & ST MODEL \\
\hline$M S, K$ & $0.14(0.12)$ & $0.15(0.10)$ & $0.19(0.10)$ & $0.16(0.10)$ & $0.16(0.12)$ \\
\hline$M S, D$ & $0.28(0.05)$ & $0.29(0.05)$ & $0.33(0.06)$ & $0.31(0.06)$ & $0.31(0.06)$ \\
\hline$M S, A S$ & $1.02(0.27)$ & $0.99(0.27)$ & $0.95(0.53)$ & $1.01(0.25)$ & $1.00(0.28)$ \\
\hline$D, K$ & $0.06(0.10)$ & $0.07(0.09)$ & $0.01(0.09)$ & $0.05(0.10)$ & $0.06(0.10)$ \\
\hline$D, A S$ & $0.50(0.14)$ & $0.50(0.14)$ & $0.59(0.11)$ & $0.55(0.13)$ & $0.54(0.15)$ \\
\hline$K, A S$ & $0.36(0.21)$ & $0.36(0.18)$ & $0.41(0.15)$ & $0.39(0.16)$ & $0.37(0.20)$ \\
\hline
\end{tabular}

${ }^{a}$ Estimated asymptotic standard errors in parentheses. $M S=$ Medical Staff, $A S=$ Administrative Staff, $D=$ Drugs, $K=$ Capital (number of beds). 
Table 6. Estimates of Shadow elasticities of input substitutability by scaled values of the average output and DRG weight $\left(\mathrm{PB}_{\mathrm{G}}\right.$ model, average input prices) ${ }^{\mathrm{a}}$

\begin{tabular}{|c|c|c|c|c|c|c|c|}
\hline \multirow{3}{*}{ MS, K } & \multirow{3}{*}{$\begin{array}{l}\text { Scaling procedure for } \\
\text { the output }(Y) \\
\lambda_{Y}=0.25\end{array}$} & \multicolumn{6}{|c|}{ Scaling procedure for DRG weight $(D R G W)$} \\
\hline & & \multicolumn{2}{|c|}{$\lambda_{D R G W}=0.50$} & \multicolumn{2}{|c|}{$\begin{array}{c}\lambda_{D R G W}=1 \\
\text { (average value) }\end{array}$} & \multicolumn{2}{|c|}{$\lambda_{D R G W}=2$} \\
\hline & & -1.20 & $(1.52)$ & -0.34 & $(0.51)$ & 0.26 & $(0.32)$ \\
\hline & $\lambda_{Y}=0.50$ & -0.42 & $(0.54)$ & -0.05 & $(0.22)$ & 0.26 & $(0.23)$ \\
\hline & $\lambda_{Y}=1$ (average value) & 0.00 & $(0.24)$ & 0.14 & $(0.12)$ & 0.26 & $(0.16)$ \\
\hline & $\lambda_{Y}=2$ & 0.23 & $(0.16)$ & 0.26 & $(0.11)$ & 0.28 & $(0.16)$ \\
\hline & $\lambda_{Y}=3$ & 0.39 & $(0.19)$ & 0.34 & $(0.15)$ & 0.30 & $(0.19)$ \\
\hline \multirow[t]{5}{*}{$M S, D$} & $\lambda_{Y}=0.25$ & -0.75 & $(0.53)$ & 0.04 & $(0.14)$ & 0.48 & $(0.16)$ \\
\hline & $\lambda_{Y}=0.50$ & -0.19 & $(0.18)$ & 0.18 & $(0.08)$ & 0.45 & $(0.11)$ \\
\hline & $\lambda_{Y}=1$ (average value) & 0.12 & (0.08) & 0.28 & $(0.05)$ & 0.42 & $(0.08)$ \\
\hline & $\lambda_{Y}=2$ & 0.30 & $(0.07)$ & 0.36 & $(0.05)$ & 0.40 & (0.09) \\
\hline & $\lambda_{Y}=3$ & 0.41 & $(0.12)$ & 0.41 & $(0.09)$ & 0.41 & $(0.12)$ \\
\hline \multirow[t]{5}{*}{$M S, A S$} & $\lambda_{Y}=0.25$ & 1.01 & $(0.22)$ & 1.01 & $(0.24)$ & 1.02 & $(0.29)$ \\
\hline & $\lambda_{Y}=0.50$ & 1.01 & $(0.24)$ & 1.02 & $(0.26)$ & 1.02 & $(0.29)$ \\
\hline & $\lambda_{Y}=1$ (average value) & 1.02 & $(0.25)$ & 1.02 & $(0.27)$ & 1.02 & $(0.29)$ \\
\hline & $\lambda_{Y}=2$ & 1.02 & $(0.28)$ & 1.02 & $(0.28)$ & 1.02 & $(0.29)$ \\
\hline & $\lambda_{Y}=3$ & 1.03 & $(0.31)$ & 1.02 & $(0.30)$ & 1.02 & $(0.29)$ \\
\hline \multirow[t]{5}{*}{$D, K$} & $\lambda_{Y}=0.25$ & -1.61 & (1.33) & -0.45 & $(0.43)$ & 0.22 & $(0.29)$ \\
\hline & $\lambda_{Y}=0.50$ & -0.64 & $(0.43)$ & -0.14 & (0.17) & 0.22 & $(0.21)$ \\
\hline & $\lambda_{Y}=1$ (average value) & -0.14 & $(0.19)$ & 0.06 & $(0.10)$ & 0.21 & $(0.15)$ \\
\hline & $\lambda_{Y}=2$ & 0.14 & $(0.14)$ & 0.19 & $(0.11)$ & 0.22 & $(0.16)$ \\
\hline & $\lambda_{Y}=3$ & 0.31 & $(0.19)$ & 0.27 & $(0.16)$ & 0.24 & $(0.20)$ \\
\hline \multirow[t]{5}{*}{$D, A S$} & $\lambda_{Y}=0.25$ & -0.57 & $(0.58)$ & 0.25 & $(0.20)$ & 0.68 & $(0.18)$ \\
\hline & $\lambda_{Y}=0.50$ & 0.00 & $(0.25)$ & 0.39 & $(0.15)$ & 0.65 & $(0.15)$ \\
\hline & $\lambda_{Y}=1$ (average value) & 0.33 & $(0.17)$ & 0.50 & $(0.14)$ & 0.63 & $(0.15)$ \\
\hline & $\lambda_{Y}=2$ & 0.52 & $(0.16)$ & 0.57 & $(0.15)$ & 0.62 & $(0.17)$ \\
\hline & $\lambda_{Y}=3$ & 0.63 & $(0.19)$ & 0.63 & $(0.18)$ & 0.62 & $(0.19)$ \\
\hline \multirow[t]{5}{*}{$K, A S$} & $\lambda_{Y}=0.25$ & -1.00 & $(1.58)$ & -0.13 & $(0.57)$ & 0.50 & $(0.36)$ \\
\hline & $\lambda_{Y}=0.50$ & -0.21 & $(0.60)$ & 0.17 & $(0.29)$ & 0.50 & $(0.27)$ \\
\hline & $\lambda_{Y}=1$ (average value) & 0.21 & $(0.31)$ & 0.36 & $(0.21)$ & 0.50 & $(0.23)$ \\
\hline & $\lambda_{Y}=2$ & 0.46 & $(0.24)$ & 0.49 & $(0.20)$ & 0.51 & $(0.24)$ \\
\hline & $\lambda_{Y}=3$ & 0.62 & $(0.26)$ & 0.58 & $(0.23)$ & 0.53 & $(0.27)$ \\
\hline
\end{tabular}

${ }^{a}$ Estimated asymptotic standard errors in parentheses. Bold typeface values indicate 10\% (or lower) significance level. $M S=$ Medical Staff, $A S=$ Administrative Staff, $D=$ Drugs, $K=$ Capital (number of beds). 